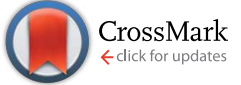

Cite this: RSC Adv., 2015, 5, 57912

\title{
Dimeric resorcinarene salt capsules with very tight encapsulation of anions and guest molecules $\dagger$
}

\author{
Fangfang Pan, N. Kodiah Beyeh* and Kari Rissanen*
}

Received 20th May 2015

Accepted 25th June 2015

DOI: $10.1039 / \mathrm{c} 5 \mathrm{ra11905g}$

www.rsc.org/advances

Crystallization of $\mathrm{N}$-cyclohexyl ammonium resorcinarene triflate from methanol results in a dimeric capsule capable of trapping two triflate anions and two methanol molecules within a $341 \AA^{3}$ cavity while with 1,4-dioxane as a guest it forms a new larger dimeric capsule with volume of $679 \AA^{3}$ encapsulating four 1,4-dioxane and four water molecules, resulting in packing coefficients of 0.75 and 0.67 , respectively.

The concerted utilization of multiple weak interactions such as electrostatic forces, hydrogen bonding, cation $\cdots \pi,-\mathrm{CH} \cdots \pi$ and $\pi \cdots \pi$ interactions in the design of functional assemblies, is a growing area of contemporary supramolecular chemistry with potential applications in biology and materials chemistry. ${ }^{1}$ Resorcinarenes are an important class of receptor compounds and/or building blocks in supramolecular chemistry. ${ }^{2}$ In their $C_{4 \mathrm{v}}$ conformation, intramolecular hydrogen bonds between adjacent phenolic hydroxyl groups help maintain the bowl shape cavity suitable for guest binding. ${ }^{2}$ These macrocyclic host compounds manifest a multitude of molecular recognition events, resulting in host-guest assemblies such as $1: 1$ inclusion complexes, ${ }^{3}$ dimeric or hexameric capsular ${ }^{4}$ assemblies and nano-tubular ${ }^{5}$ structures in the presence of specific guest compounds under suitable conditions.

Anions have a major role in biological processes. ${ }^{6}$ Examples of anions or anionic compounds in biology include many enzyme substrates and cofactors. ${ }^{6}$ Anions are generally larger than their isoelectronic cations with wider solvation properties and are more sensitive to $\mathrm{pH}$ with a larger range of geometric/

University of Jyvaskyla, Department of Chemistry, NanoScience Center, P. O: Box 35, 40014 Jyvaskyla, Finland. E-mail: kari.t.rissanen@jyu.fi; ngong.k.beyeh@jyu.fi; Tel: +358 505623721

$\dagger$ Electronic supplementary information (ESI) available: Synthetic details, NMR analyses and details about the single crystal data collection, data processing, and structures refinement results; intermolecular hydrogen bonded 2D networks for $\left[(\mathrm{OTf} \cdot \mathrm{MeOH})_{2} @\left(4(\mathrm{OTf})_{3} \mathrm{MeOH}\right)_{2}\right.$ and $\left(2 \times 1,4 \text {-dioxane } \cdot 2 \times \mathrm{H}_{2} \mathrm{O}\right)_{2} @$ $\left(4(\mathrm{OTf})_{4}\right)_{2}$. CCDC 1401637 and 1401638, respectively. For ESI and crystallographic data in CIF or other electronic format see DOI: 10.1039/c5ra11905g structural modulations. ${ }^{6}$ These characteristics make the binding/recognition of anions more challenging when compared to cation binding. ${ }^{6}$ However, anion binding receptors and their applications as sensors, or their use in ions channels is widely reported. ${ }^{7}$ Anions can also be used to template the formation of ionic and metal coordination cages as well as interlocked systems. ${ }^{8}$ The propensity of anions to form hydrogen bonds and be involved in electrostatic interactions implies, incorporating these characteristics in the design of molecular receptors, could lead to very efficient anion receptors. ${ }^{9}$

The $N$-alkyl ammonium resorcinarene halides, NARXs, are obtained by cleaving the corresponding tetrabenzoxazines ${ }^{10}$ with mineral acids (usually $\mathrm{HCl}$ and $\mathrm{HBr}$ ) under refluxing conditions. ${ }^{11}$ The concave cavity of the resorcinarenes is maintained in these large organic halide salts through a strong circular intramolecular hydrogen bonded cation-anion $\left(\cdots \mathrm{NR}_{2} \mathrm{H}_{2}{ }^{+} \cdots \mathrm{X}^{-} \cdots\right)_{4}$ seam between the ammonium groups and the halides anions. ${ }^{11}$ These halide salts have been shown to be excellent halogen bond acceptors and manifest themselves as deep cavity cavitands ${ }^{12}$ and halogen bonded capsules. ${ }^{13}$ We have recently investigated the binding modes with non-halide anions: picrate (aromatic planar), nitrate (trigonal planar) and triflate (ellipsoidal). ${ }^{14}$ While the picrate salt was synthesized from the corresponding cleavage of the tetrabenzoxazine with picric acid, the nitrate and triflate were obtained through anion exchange of the corresponding chloride salts with silver nitrate and silver triflate, respectively. ${ }^{14}$ Although the non-spherical anion-based NAR's are less symmetrical, the main features such as the inherited "bowl" shape, the circular hydrogen bonded cation-anion seam, and the guest binding properties are retained. Compared to the spherical halides, the larger nonspherical anions broaden the opening of the "bowl", which enables the capture of either larger-sized or multiple guest molecules. This "opening" of the cavity allows new guest binding motifs to the resorcinarene family.

Herein, we describe the synthesis and characterization of the $N$-cyclohexyl ammonium resorcinarene triflate salt (NAROTf). 
The X-ray diffraction study for the crystals of NAROTf, $4(\mathrm{OTf})_{4}$, obtained from pure methanol or methanol with 1,4-dioxane as a guest molecule, reveals two different dimeric capsules with different cavity sizes and encapsulation of either four or eight guests.

The $4(\mathrm{OTf})_{4}$, was synthesized according to modified procedures. ${ }^{10,11,14}$ In the reaction, the parent tetrabenzoxazine 3 is converted to the ammonium salt $\mathbf{4}(\mathrm{OTf})_{4}$ by refluxing in the presence of triflic acid in isopropanol (Scheme 1). The ${ }^{1} \mathrm{H}$ NMR in DMSO- $d_{6}$ reveals the salts to be as symmetrical as the corresponding halide analogues NARXs in solution. ${ }^{11}$ However, the effect of the anions which are participating in the intramolecular hydrogen bond seam involving the $-\mathrm{NH}_{2}$ and $-\mathrm{OH}$ groups of the resorcinarenes is apparent from the signal changes of the $4(\mathrm{OTf})_{4}$ protons as compared to the $4(\mathrm{Cl})_{4} / 4(\mathrm{Br})_{4}$ analogues (Fig. $\mathrm{S} 1 \dagger$ ).

Recent studies have shown that 1,4 -dioxane, ${ }^{15}$ small alcohols, ${ }^{11} N$-alkyl and $N$-aryl amides ${ }^{15}$ as well as diamides ${ }^{16}$ with varying spacer lengths are suitable guests for the NARXs. Interactions such as $-\mathrm{CH} \cdots \pi$ between the guests and the $\pi$-cavity of the hosts as well as hydrogen bond interactions between the guests and cation-anion seam of the hosts are mainly responsible for these host-guest complexes. Large non-spherical anions have the ability to disrupt the cation-anion seam and subsequently affect the inner cavity of the hosts. ${ }^{14}$ The 1,4-dioxane, being a particularly excellent guest for the NARXs, ${ }^{15}$ was utilized to study the host-guest properties of $4(\mathrm{OTf})_{4}$. In $\mathrm{CDCl}_{3}$ at $300 \mathrm{~K}$, the ${ }^{1} \mathrm{H}$ NMR of $4(\mathrm{OTf})_{4}$ shows two signals for the $-\mathrm{NH}_{2}$ protons of the host in a $1: 3$ ratio (Fig. 1a). The $-\mathrm{NH}_{2}$ signals of the NARXs usually appear as a single broad signal under the same conditions. ${ }^{11,12}$ This indicates that one $-\mathrm{NH}_{2}$ group has different hydrogen bonds with the triflate anion as compared to the other three $-\mathrm{NH}_{2}$ groups, suggesting that the symmetrical cation-anion hydrogen bond seam is broken and one of the triflates resides inside the cavity. After the addition of one equivalent of 1,4-dioxane as the guest, the two separate $-\mathrm{NH}_{2}$ signals merge into one slightly downfield signal (Fig. 1b). The downfield shift of the $-\mathrm{NH}_{2}$ signals is attributed to the incavity hydrogen bond formation with the 1,4-dioxane guest. ${ }^{11,12}$ The complexation induced up-field shift of the 1,4-dioxane protons also confirms its location in the cavity of the host $\mathbf{4}(\mathrm{OTf})_{4}$. Thus in the presence of 1,4-dioxane, the in-cavity triflate is replaced by the 1,4-dioxane guest. The replaced triflate then moves to the cation-anion seam making it symmetric and thus the $-\mathrm{NH}_{2}$ protons appear as one signal (Fig. 1).

Single crystal X-ray diffraction study gave a detail picture of the solid state properties of the host with and without suitable

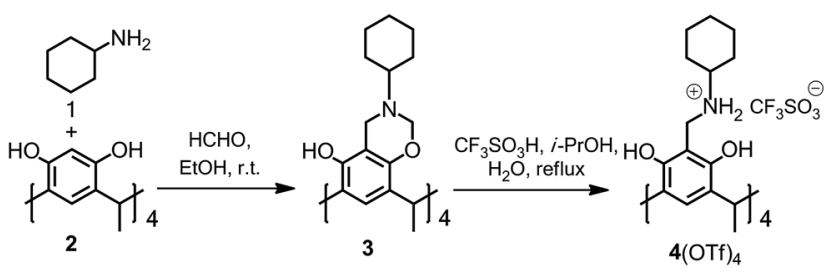

Scheme 1 Synthesis of $4(\mathrm{OTf})_{4}$.

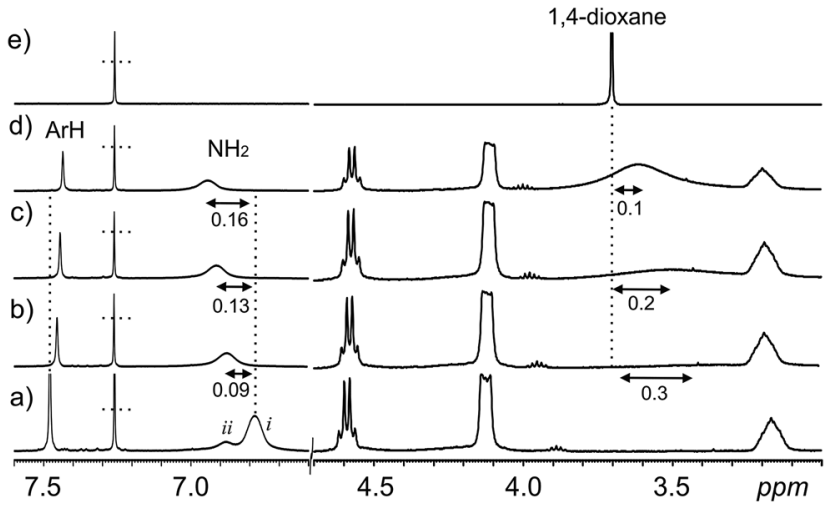

Fig. 1 The ${ }^{1} \mathrm{H}$ NMR spectra in $\mathrm{CDCl}_{3}$ at $300 \mathrm{~K}$ of: (a) $4(\mathrm{OTf})_{4}(10 \mathrm{mM})$, (b) $1: 1$, (c) $1: 2$, (d) $1: 4$ host-guest mixtures of $4(\mathrm{OTf})_{4}$ and 1,4-dioxane, (e) 1,4-dioxane (10 mM). Dashed lines give an indication of the spectra changes with values in ppm; $i$ and $i i$ reflects the different environment of the $-\mathrm{NH}_{2}$ protons in a $3: 1$ ratio.

guest(s) as well as the interactions between the large triflate anion and the cationic moieties of the resorcinarene core. Fortunately, suitable single crystals of $\mathbf{4}(\mathrm{OTf})_{4}$ with and without 1,4-dioxane molecule were obtained, revealing the structural changes induced by the large triflate anions and the guest molecules on the conformation of the resorcinarene salt skeleton.

Crystallization of $4(\mathrm{OTf})_{4}$ from wet methanol resulted in the dimeric capsule $(\mathrm{OTf} \cdot \mathrm{MeOH})_{2} @\left(\mathbf{4}(\mathrm{OTf})_{3} \mathrm{MeOH}\right)_{2}$. The symmetry of $4(\mathrm{OTf})_{4}$ observed in DMSO- $d_{6}$ solution is broken in the solid state. The resorcinarene skeleton is heavily distorted and the circular $\left(\cdots \mathrm{NR}_{2} \mathrm{H}_{2}{ }^{+} \cdots \mathrm{X}^{-} \cdots\right)_{4}$ hydrogen bond seam found in the corresponding $\mathbf{4}(\mathrm{Cl})_{4} / \mathbf{4}(\mathrm{Br})_{4}$ analogues no longer exists in this structure. Instead, the hydrogen bond seam is now constructed by the four ammonium groups, three triflate anions and one $\mathrm{MeOH}$ molecule, the fourth triflate being hydrogen bonded to a $\mathrm{MeOH}$ molecule and included into the cavity of $4(\mathrm{OTf})_{3} \mathrm{MeOH}$.

The location of the triflate inside the cavity is also supported by the NMR analysis in solution. The bound $\mathrm{MeOH}$ is fixed deeply in the cavity of $4(\mathrm{OTf})_{3} \mathrm{MeOH}$ by $\mathrm{N}-\mathrm{H} \cdots \mathrm{O}_{\mathrm{MeOH}}$ and $\mathrm{O}-\mathrm{H}_{\mathrm{MeOH}} \cdots \mathrm{O}$ hydrogen bonds just below the encapsulated triflate anion, interacting with the bottom of the host cavity via $\mathrm{C}-\mathrm{H} \cdots \pi$ interactions (Fig. $2 \mathrm{~A}$ and B). One of the triflate anion in the cation-anion seam moves further away from the cavity and gives space to one of the $\mathrm{N}$-cyclohexyl ammonium arms which then moves inwards filling up the remaining space. This $N$-cyclohexyl ammonium arm appears in a gauche conformation, partially capping the cavity with the $-\mathrm{NH}_{2}$ hydrogens pointing outwards. The two in-cavity triflate anions show short F $\cdots$ F contacts with each other leading to a dimeric capsule with four (two $\mathrm{OTf}^{-}$and two $\mathrm{MeOH}$ ) included guests (Fig. 2B and C). The PLATON ${ }^{17}$ calculated volume of the cavity is $341 \AA^{3}$. The four encapsulated guests $\left(V_{\text {OTf }}=87.1 \AA^{3}\right.$ and $V_{\mathrm{MeOH}}=40.7 \AA^{3}$, $\left.2 \times 87.1+2 \times 40.87=255.6 \AA^{3}\right)$ occupy $75 \%$ of the cavity revealing a more dense packing within the cavity than in the crystal itself. ${ }^{18}$ The fact that the host cavity can be suitable for the encapsulation of the triflate anion with definite intermolecular hydrogen bonds to the hosts is particularly interesting, 
A

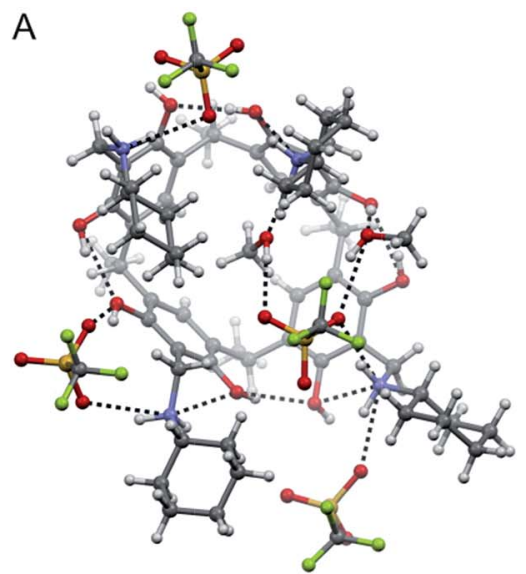

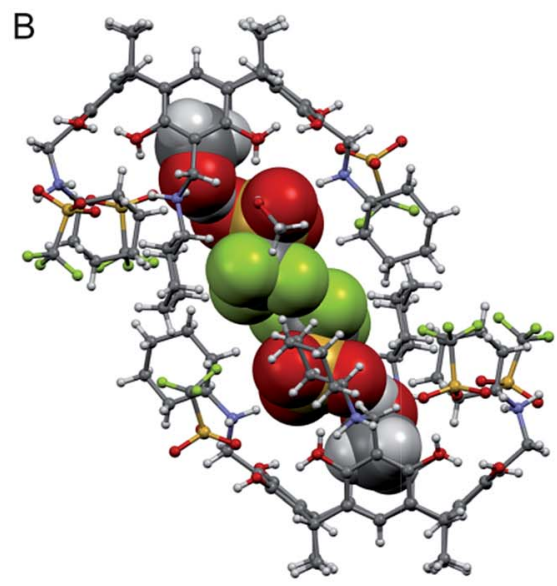

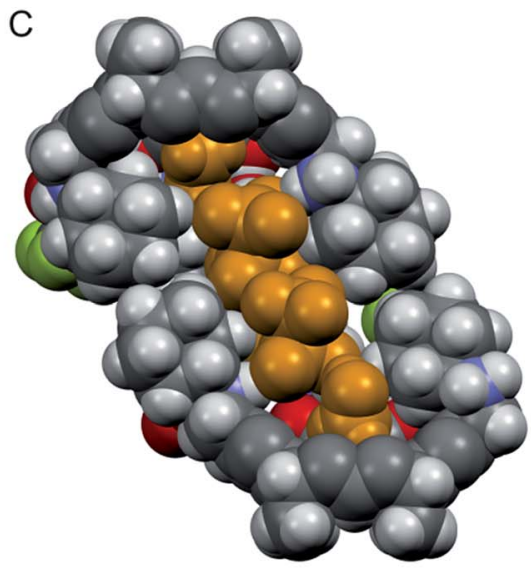

Fig. 2 X-ray structure of the dimeric capsule $(\mathrm{OTf} \cdot \mathrm{MeOH})_{2} \mathrm{Q}\left(4(\mathrm{OTf})_{3} \mathrm{MeOH}\right)_{2}$ : (A) one half of the capsule with intramolecular hydrogen bonds shown in black dotted lines. (B) The dimeric capsule with encapsulated guests in CPK mode. (C) Sliced CPK model to show the encapsulation of the guests in the dimeric capsule. The in-cavity guests are shown in gold colour.

A

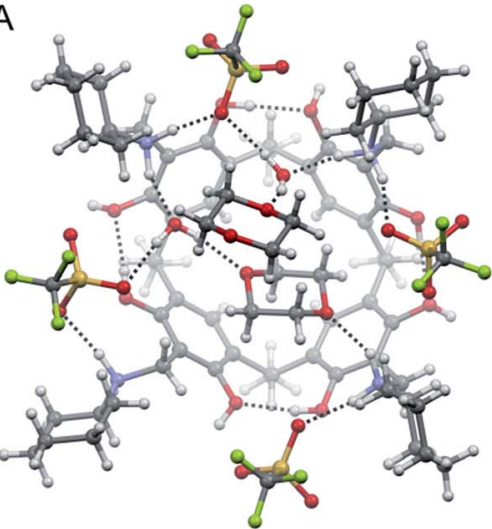

B

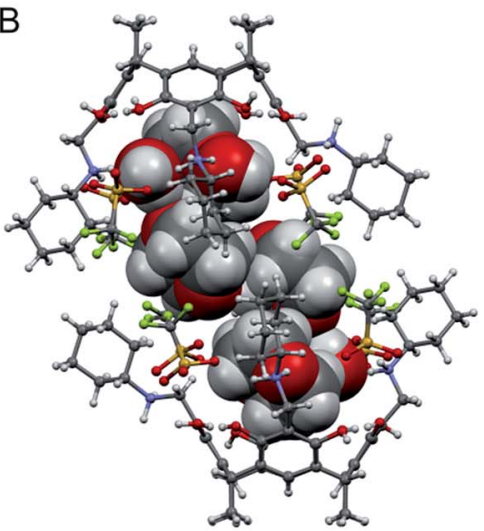

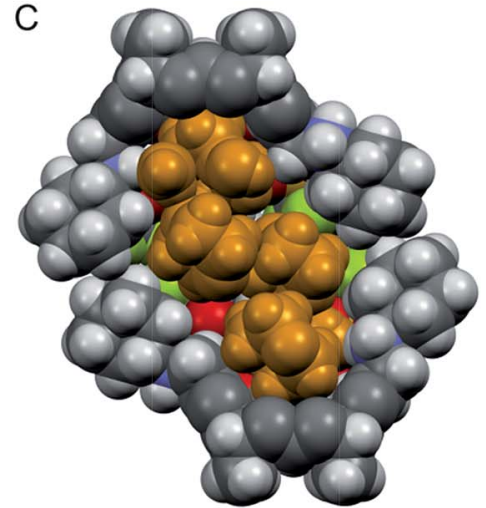

Fig. 3 X-ray structure of the dimeric capsule $\left(2 \times 1 \text {,4-dioxane } \cdot 2 \times \mathrm{H}_{2} \mathrm{O}\right)_{2}\left(\mathrm{a}\left(4(\mathrm{OTf})_{4}\right)_{2}\right.$ : (A) one half of the capsule with intramolecular hydrogen bonds shown in black dotted lines. (B) The dimeric capsule with encapsulated guests in CPK mode. (C) Sliced CPK mode to show the encapsulation of the guests in the dimeric capsule. The in-cavity guests are shown in gold colour.

since it highlights the versatility of NARXs as potential receptors for anions.

Evaporation of a wet methanol solution containing $\mathbf{4}(\mathrm{OTf})_{4}$ with a small amount of 1,4-dioxane (which is known to be excellent guest for NARXs ${ }^{15}$ ) resulted in a capsular host-guest complex $\left(2 \times 1 \text {,4-dioxane. } 2 \times \mathrm{H}_{2} \mathrm{O}\right)_{2} @\left(4(\mathrm{OTf})_{4}\right)_{2}$. In the presence of 1,4-dioxane guest, the four triflate anions in the structure are located on the cation-anion seam as in the other symmetrical NARXs ${ }^{11}$ (Fig. 3A). The concave cavity of the resorcinarene is broadened with the opposite $\mathrm{N} \cdots \mathrm{N}$ separation of 10.466 and $10.671 \AA$, compared to its halide analogues. Thus the cavity is larger than normal ${ }^{11}$ and traps two 1,4-dioxane and two water molecules. The 1,4-dioxane at the bottom of the cavity is tightly bound from its $\mathrm{O}$-atoms to the host $\mathbf{4}(\mathrm{OTf})_{4}$ via one ammonium group and to one water molecule, which is hydrogen bonded to a triflate anion and to another ammonium group on the other aside of each cavity. The upper 1,4-dioxane molecule is hydrogen bonded only with one of its O-atom to the water molecules, which is hydrogen bonded to the third ammonium group and a second triflate anion (Fig. 3A). The weak $\mathrm{C}-\mathrm{H} \cdots \mathrm{O}$ hydrogen bonds supplemented by intermolecular $\mathrm{F} \cdots \mathrm{F}$ contacts resulting in the dimerization of capsule halves, encapsulating a total of eight ordered molecules (Fig. 3B) in the confined cavity with a large cavity volume of $679 \AA^{3} \cdot{ }^{17}$ The eight guests $\left(V_{\text {Dioxane }}=94.3 \AA^{3}\right.$ and $V_{\mathrm{H}_{2} \mathrm{O}}=19.4 \AA^{3}, 4 \times 94.3+4 \times$ $19.4=454.8 \AA^{3}$ ) occupy $67 \%$ of the interior cavity, still much more dense than the often referred optimal packing of $55 \% .{ }^{18}$ Rebek et $a l .^{18}$ reported exceptions to the $55 \pm 0.9 \%$ rule in rare cases with a maximum of $75 \%$, while Bruce et al. ${ }^{19}$ observed a higher packing efficiency of $82 \%$ with deep cavity cavitands. The $\left(2 \times 1 \text {,4-dioxane } \cdot 2 \times \mathrm{H}_{2} \mathrm{O}\right)_{2} @\left(4(\mathrm{OTf})_{4}\right)_{2}$ capsule thus represents one of the most dense dimeric capsules.

\section{Conclusions}

In summary, the NAROTf, $4(\mathrm{OTf})_{4}$, was synthesized by opening the tetrabenzoxazine ring with triflic acid. ${ }^{10,11,14}$ The NMR studies in $\mathrm{CDCl}_{3}$ and the single crystal X-ray structure from 
crystals obtained from wet methanol, showed the deformation of the normally existing cation-anion seam ${ }^{11}$ with an inclusion of one of the triflate anion into the cavity. Upon addition of small amount of 1,4-dioxane to this system, the ${ }^{1} \mathrm{H}$ NMR in $\mathrm{CDCl}_{3}$ proves that 1,4-dioxane will readily occupy the resorcinarene cavity thus replacing the encapsulated triflate and driving it out from the cavity to re-from the normal circular cation-anion hydrogen bonded seam. In the solid state, the NAROTf forms two structurally different dimeric capsules. From wet methanol a six-component dimeric capsule $(\mathrm{OTf} \cdot \mathrm{MeOH})_{2} @\left(\mathbf{4}(\mathrm{OTf})_{3} \mathrm{MeOH}\right)_{2}$ encapsulating two triflate anions and two methanol molecules is formed, while 1,4-dioxane being present, a 10-component dimeric capsule $\left(2 \times 1 \text {,4-dioxane } \cdot 2 \times \mathrm{H}_{2} \mathrm{O}\right)_{2} @\left(4(\mathrm{OTf})_{4}\right)_{2}$ is formed, showing a very tight encapsulation of four 1,4-dioxane and four water molecules. Both capsules were analysed by single crystal X-ray diffraction studies. The $(\mathrm{OTf} \cdot \mathrm{MeOH})_{2} @\left(\mathbf{4}(\mathrm{OTf})_{3} \mathrm{MeOH}\right)_{2}$ capsule has a packing coefficient of 0.75 , induced by the enhanced short $\mathrm{F} \cdots \mathrm{F}$ contacts of the two encapsulated and hydrogen bonded triflate $\cdots \mathrm{H}-\mathrm{OMe}$ complexes. The fact that the resorcinarene salt cavity was found to be suitable for the encapsulation of the triflate anion with definite intermolecular hydrogen bonds to the hosts is particularly interesting, since it opens the possibility of these systems to recognize anions under certain conditions. The 10-component capsule $(2 \times 1$,4-dioxane· $\left.2 \times \mathrm{H}_{2} \mathrm{O}\right)_{2} @\left(4(\mathrm{OTf})_{4}\right)_{2}$ has a packing coefficient of 0.67 , a very high or maybe highest number of bound (eight) neutral guest molecules inside the confined space of a dimeric capsule. Weak F $\cdots$ F contacts were observed in both dimeric capsules. Despite their generally weak nature, they seem to be crucial for the capsule formation. The resorcinarene salts, in short NARXs, are surprisingly versatile receptors that can recognize neutral compounds, act as halogen bond acceptors and now encapsulate anions through the combination of weak interactions.

\section{Acknowledgements}

Academy of Finland (KR. grant no. 265328 and 263256, NKB no. 258653) and the University of Jyväskylä are kindly acknowledged for financial support.

\section{Notes and references}

1 (a) J. C. Ma and D. A. Dougherty, Chem. Rev., 1997, 97, 1303; (b) G. R. Desiraju, Angew. Chem., Int. Ed. Engl., 1995, 34, 2311; (c) T. Steiner, Angew. Chem., Int. Ed., 2002, 41, 48; (d) C. G. Claessens and J. F. Stoddart, J. Phys. Org. Chem., 1997, 10, 254; (e) E. A. Meyer, R. K. Castellano and F. Diederich, Angew. Chem., Int. Ed., 2003, 42, 1210; $(f)$ J. W. Steed and J. L. Atwood, in Supramolecular Chemistry, John Wiley \& Sons, Ltd, 2009, p. 591.

2 (a) P. Timmerman, W. Verboom and D. N. Reinhoudt, Tetrahedron, 1996, 52, 2663; (b) J. L. Atwood and A. Szumna, Chem. Commun., 2003, 8, 940; (c) K. Rissanen, Angew. Chem., Int. Ed., 2005, 44, 3652.

3 (a) N. K. Beyeh, D. P. Weimann, L. Kaufmann, C. A. Schalley and K. Rissanen, Chem.-Eur. J., 2012, 18, 5552; (b)
E. Kalenius, T. Kekäläinen, R. Neitola, K. Beyeh, K. Rissanen and P. Vainiotalo, Chem.-Eur. J., 2008, 14, 5220. 4 (a) N. K. Beyeh and K. Rissanen, Isr. J. Chem., 2011, 51, 769; (b) N. K. Beyeh, A. Valkonen and K. Rissanen, Supramol. Chem., 2009, 21, 142; (c) H. Mansikkamäki, C. A. Schalley, M. Nissinen and K. Rissanen, New J. Chem., 2005, 29, 116; (d) L. Avram and Y. Cohen, J. Am. Chem. Soc., 2002, 124, 15148; (e) M. M. Conn and J. Rebek, Chem. Rev., 1997, 97, 1647; $(f)$ N. K. Beyeh, M. Kogej, A. Åhman, K. Rissanen and C. A. Schalley, Angew. Chem., Int. Ed., 2006, 45, 5214; (g) J. Kang and J. Rebek, Nature, 1996, 382, 239.

5 (a) H. Mansikkamäki, M. Nissinen and K. Rissanen, Angew. Chem., Int. Ed., 2004, 43, 1243; (b) H. Mansikkamäki, S. Busi, M. Nissinen, A. Åhman and K. Rissanen, Chem.Eur. J., 2006, 12, 4289.

6 (a) S.-K. Ko, S. K. Kim, A. Share, V. M. Lynch, J. Park, W. Namkung, W. Van Rossom, N. Busschaert, P. A. Gale, J. L. Sessler and I. Shin, Nat. Chem., 2014, 6, 885; (b) J. L. Sessler, P. I. Sansom and A. Andrievsky, Supramolecular Chemistry of Anions, ed. A. Bianchi, K. Bowman-James and E. García-Espana, Wiley-VCH, New York, 1997, p. 1; (c) P. D. Beer and P. A. Gale, Angew. Chem., Int. Ed., 2001, 40, 486; (d) P. Chakrabarti, J. Mol. Biol., 1993, 234, 463.

7 (a) S. J. Edwards, H. Valkenier, N. Busschaert, P. A. Gale and A. P. Davis, Angew. Chem., Int. Ed., 2015, 54, 4592; (b) N. Busschaert, L. E. Karagiannidis, M. Wenzel, C. J. E. Haynes, N. J. Wells, P. G. Young, D. Makuc, J. Plavec, K. A. Jolliffe and P. A. Gale, Chem. Sci., 2014, 5, 1118.

8 (a) R. A. Bissell, E. Cordova, A. E. Kaifer and J. F. Stoddart, Nature, 1994, 369, 133; (b) P. R. Ashton, R. Ballardini, V. Balzani, I. Baxter, A. Credi, M. C. T. Fyfe, M. T. Gandolfi, M. Gómez-López, M.-V. Martínez-Díaz, A. Piersanti, N. Spencer, J. F. Stoddart, M. Venturi, A. J. P. White and D. J. Williams, J. Am. Chem. Soc., 1998, 120, 11932; (c) J. Wook Lee, K. Kim and K. Kim, Chem. Commun., 2001, 1042-1043; (d) A. M. Elizarov, S.-H. Chiu and J. F. Stoddart, J. Org. Chem., 2002, 67, 9175; (e) C. M. Keaveney and D. A. Leigh, Angew. Chem., Int. Ed., 2004, 43, 1222-1224; (f) R. Vilar, Angew. Chem., Int. Ed., 2003, 42, 1460.

9 (a) E. Graf and J.-M. Lehn, J. Am. Chem. Soc., 1976, 98, 6403; (b) J.-M. Lehn, E. Sonveaux and A. K. Willard, J. Am. Chem. Soc., 1978, 100, 4914; (c) A. Echavarren, A. Galan, J.-M. Lehn and J. De Mendoza, J. Am. Chem. Soc., 1989, 111, 4994; (d) M. W. Hosseini and J.-M. Lehn, Helv. Chim. Acta, 1986, 69, 587; (e) M. W. Hosseini and J.-M. Lehn, J. Am. Chem. Soc., 1982, 104, 3525; ( $f$ ) B. Dietrich, J. Guilhem, J.-M. Lehn, C. Pascard and E. Sonveaux, Helv. Chim. Acta, 1984, 67, 91; $(g)$ M. Cametti and K. Rissanen, Chem. Commun., 2009, 2809.

10 (a) C. Schmidt, K. Airola, V. Böhmer, W. Vogt and K. Rissanen, Tetrahedron, 1997, 53, 17691; (b) K. Airola, V. Böhmer, E. F. Paulus, K. Rissanen, C. Schmidt, I. Thondorf and W. Vogt, Tetrahedron, 1997, 53, 10709; (c) N. K. Beyeh, A. Valkonen and K. Rissanen, Org. Lett., 2010, 12, 1392. 
11 (a) A. Shivanyuk, T. P. Spaniol, K. Rissanen, E. Kolehmainen and V. Böhmer, Angew. Chem., Int. Ed., 2000, 39, 3497; (b) N. K. Beyeh, M. Cetina, M. Löfman, M. Luostarinen, A. Shivanyuk and K. Rissanen, Supramol. Chem., 2010, 22, 737.

12 (a) N. K. Beyeh, M. Cetina and K. Rissanen, Chem. Commun., 2014, 50, 1959; (b) N. K. Beyeh, A. Valkonen, S. Bhowmik, F. Pan and K. Rissanen, Org. Chem. Front., 2015, 2, 340.

13 N. K. Beyeh, F. Pan and K. Rissanen, Angew. Chem., Int. Ed., 2015, 54, 7303.

14 N. K. Beyeh, M. Cetina and K. Rissanen, Cryst. Growth Des., 2012, 12, 4919.
15 N. K. Beyeh, A. Ala-Korpi, M. Cetina, A. Valkonen and K. Rissanen, Chem.-Eur. J., 2014, 20, 15144.

16 N. K. Beyeh, A. Ala-Korpi, F. Pan, H. Jo, E. V. Anslyn and K. Rissanen, Chem.-Eur. J., 2015, 21, 9556.

17 A. L. Spek, Acta Crystallogr., Sect. D: Biol. Crystallogr., 2009, 65, 148.

18 S. Mecozzi and J. Rebek, Chem.-Eur. J., 1998, 4, 1016.

19 L. S. Kaanumalle, C. L. D. Gibb, B. C. Gibb and V. Ramamurthy, J. Am. Chem. Soc., 2005, 127, 3674. 